\title{
O drama mítico-expressionista de Consuelo de Castro: uma análise de Marcha a Ré (1986) ${ }^{i}$
}

\author{
Renato Cândido da Silva* \\ Orlando Luiz de Araújo **
}

Resumo: A dramaturga Consuelo de Castro, ao longo de sua trajetória no teatro brasileiro, escreveu diversos dramas que dialogam com os mitos da Antiguidade clássica - como é o caso de Marcha a Ré (1986), peça que mantém estreita relação com o mito de Orfeu e Eurídice. Partindo do pressuposto de que esta obra se trata de um drama subjetivo, devido à sua construção dramática, pois a unidade de ação é substituída pela unidade do Eu, este artigo tem como objetivo analisar Marcha a Ré, levando em consideração a intrínseca relação entre o referido mito greco-romano e o teatro expressionista.

Palavras-chave: Mito. Teatro Expressionista. Marcha a Ré. Consuelo de Castro.

Abstract: The playwright Consuelo de Castro, throughout her trajectory in Brazilian theater, wrote several dramas that dialogue with the myths of classical antiquity - as is the case of Marcha a Ré (1986), a play that has a close relationship with the myth of Orpheus and Eurydice. Based on the assumption that this work is a subjective drama, due to its dramatic construction, since the unity of action is replaced by the unity of the Self, this article aims to analyze Marcha a Ré, taking into account the intrinsic relationship between the referred Greco-Roman myth and the expressionist theater.

Keywords: Myth. Expressionist Theater. Marcha a Ré. Consuelo de Castro.

Résumé La dramaturge Consuelo de Castro, loin de sa trajectoire dans le théâtre brésilien, a écrit plusieurs drames qui dialoguent avec les mythes de l'antiquité classique - comme c'est le cas de Marcha a Ré (1986), dont la pièce a un rapport étroit avec le mythe d'Orphée et Eurydice. Partant de l'hypothèse que cette œuvre est un drame subjectif, en raison de sa construction dramatique, puisque l'unité d'action est remplacée par l'unité du Soi, cet article vise à analyser la Marcha a Ré, en tenant compte de la relation intrinsèque entre le fait référence au mythe gréco-romain et au théâtre expressionniste.

Mots-clés: Mythe. Théâtre expressionniste. Marcha a Ré. Consuelo de Castro.

\footnotetext{
${ }^{\mathrm{i}}$ Este artigo teve o apoio da Coordenação de Aperfeiçoamento de Pessoal de Nível Superior Brasil (CAPES) - Código de Financiamento oo1.

* Doutorando em Letras do Programa de Pós-Graduação em Letras da Universidade Federal do Ceará (UFC). https://orcid.org/oooo-0001-8976-8208

** Doutor em Letras Clássicas pela Universidade de São Paulo (USP). Professor de Língua e Literatura Grega da Graduação em Letras e do Programa de Pós-Graduação em Letras da Universidade Federal do Ceará (UFC). E-mail: orlando.araujo@ufc.br. https://orcid.org/oooo-00o1-9886-3733
}

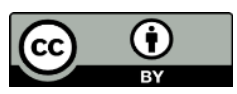




\section{Introdução}

Em 1962, aos dezesseis anos, a jovem Consuelo de Castro (1946-2016) publica sua primeira obra - trata-se do livro de poesia intitulado A Última Greve. Dois anos depois, no período em que trabalhou como contrarregra nas montagens das peças Quando as Máquinas Param e Dois Perdidos Numa Noite Suja, ambas de Plínio Marcos (1935-1999), Consuelo escreve sua primeira peça de teatro: Prova de Fogo (originalmente A Invasão dos Bárbaros). Em entrevista concedida a Daniel Schenker Wajnberg, para a Tribuna da Imprensa, Consuelo de Castro relata que, ao mostrar seu primeiro texto ao dramaturgo Plínio Marcos, este lhe disse que o diálogo era melhor do que sua poesia. Ele "pegou uma máquina de escrever, colocou no fundo do teatro e me obrigou a chegar sempre duas horas antes para escrever. Foi aí que redigi o primeiro ato de Prova de Fogo" (CASTRO apud WAJNBERG 2003, p. 1).

Depois da estreia de Consuelo de Castro na dramaturgia, vieram O Porco Ensanguentado (1972), A Cidade Impossível de Pedro Santana (1975 - originalmente Acidente de Trabalho), Implosão (1976), Último Capítulo (1976), A Corrente (1981 coautoria com Jorge Andrade e Lauro Cesar Muniz), Mel de Pedra (1985), Ao Sol do Novo Mundo (1986), Uma Caixa de Outras Coisas (1986 - coautoria com Antônio Abujamra), Hair (1987 - adaptação), O Kotô (1988), Memórias do Mar Aberto - Medeia Conta Sua História (1997), Only You (1998), Making Off (1999).

A produção dramática de Consuelo de Castro não para por aí: diversas de suas peças estão inseridas no livro Urgência e Ruptura (1989), publicado pela Editora Perspectiva. Nas palavras da autora, Urgência é uma seleção de peças escritas entre "1968 e 1978, sob a pressa rangente dos nossos fatos, teimando contra o lápis vermelho dos censores, aos quais tenho maior orgulho de ter ajudado a soterrar de trabalho, dada a abundância da matéria a ser cortada” (CASTRO, 1989, p. 10); já Ruptura, trata-se de uma triagem do que ela produziu "entre 1978 e 1988, livre ao menos do dito e maldito lápis vermelho - quando mais não seja de sua presença oficial e corpórea" (CASTRO, 1989, p. 10). Assim, no primeiro bloco de Urgência e Ruptura estão Prova de Fogo (1968), À Flor 
da Pele (1969), Caminho de Volta (1974 - originalmente Viagem de Volta) e O Grande Amor de Nossas Vidas (1978); no segundo, Louco Circo do Desejo (1983), Script-Tease (1985), Aviso Prévio (1985) e Marcha a Ré (1986 - coautoria com Emilio Alves).

Por meio desta divisão, as peças estão inseridas em dois eixos: no primeiro eixo, Consuelo se volta às urgências do momento, traçando um paralelo entre suas vivências e a conjuntura política do pós-golpe militar no Brasil; no segundo eixo estão as peças identificadas como rupturas, que podemos inseri-las, por sua vez, em dois níveis: temático e formal. Louco Circo do Desejo possui uma ruptura temática, ao passo que Script-Tease, Aviso Prévio e Marcha a Ré têm uma ruptura formal.

Ainda sobre a produção dramática de Consuelo de Castro, é importante destacar sua ligação com a mitologia greco-romana. As peças A Cidade Impossível de Pedro Santana, Memórias do Mar Aberto - Medeia Conta Sua História e Marcha a Ré dialogam, respectivamente, com os seguintes mitos da Antiguidade clássica: "Ícaro e Dédalo", “Medeia” e "Orfeu e Eurídice”. Com estes dramas, forma-se, assim, o que denominamos, na produção teatral de Consuelo de Castro, dramaturgia mítica. No caso do drama Marcha a Ré, destaca-se, ainda, uma particularidade: sua intrínseca aproximação com o teatro expressionista - o que intitulamos aqui como drama mítico-expressionista.

É, portanto, em torno desta peça que este trabalho se direciona, ou seja, analisar, na obra de Consuelo de Castro, a relação do mito greco-romano com o teatro expressionista. Mas, antes de tratarmos do drama mítico-expressionista Marcha a Ré, faz-se necessário tecer alguns apontamentos, mesmo que de forma breve, acerca do lugar de Consuelo de Castro na dramaturgia brasileira contemporânea.

\section{O lugar de Consuelo de Castro na dramaturgia brasileira contemporânea}

A partir do Golpe Militar de 1964, a dramaturgia brasileira presenciou e sofreu diversas transformações e não podemos deixar de destacar, evidentemente, o teor político das peças. No intuito de refletir sobre a problemática sociopolítica do Brasil do pós-golpe, os dramaturgos colocaram em cena personagens oriundas de uma crise política e todas as adversidades que as acometem. No caso de Consuelo de Castro, 
sempre deixou claro que seus personagens "procedem de uma crise política” (CASTRO, 1972, p. 5) e que não consegue "dissociar um personagem de um amálgama social, humano, político e histórico” (CASTRO apud RIANI, 2001, p. 2).

No texto "A respeito de Consuelo de Castro", o dramaturgo Gianfrancesco Guarnieri ressalta que a autora brasileira,

Integrada em sua realidade, não dissocia o homem da sociedade em que vive, retratando-o não como um ser isolado na procura absoluta do "a que vim e por quê?”, mas condicionado pelas relações de produção e pelo sistema social, econômico, político e cultural que o conformam. Surgindo como autora teatral em uma época de obscurantismo, quando todos os obstáculos se antepunham à honesta realização artística, Consuelo soube driblar os incentivos ao fácil desnudamento psicológico e posicionar-se solidamente ao lado de um teatro social, de um realismo crítico, buscando, através de sua experiência de vida, a expressão das contradições em que se debate a sociedade brasileira (GUARNIERI, 1978, p. 5).

A proposta da chamada "Geração de 69" (formada, sobretudo, por Antonio Bivar, José Vicente, Leilah Assunção, Isabel Câmera e Consuelo de Castro) era a de incluir nas peças os temas do momento instantâneo brasileiro, em seus aspectos estético, político, econômico e social. Assim, as peças escritas durante o regime militar (1964-1985) foram tentativas de promover a conscientização política do público por meio da encenação, pois a arte cênica era capaz de escancarar uma realidade social e política complexa. Por isso, as peças foram sistematicamente censuradas, o que dificultava a permanência dessas autoras na cena teatral. "Existe uma razão evidente: elas incomodam. O teatro da moça é inquietante: questiona, indaga, denuncia e, mais que tudo, propõe” (GUARNIERI, 1978, p. 5).

Paradoxalmente, partindo de um aspecto amplo do cenário teatral brasileiro, a partir de 1960, a dramaturgia, sobretudo a de autoria feminina, passou a ser vista de

\footnotetext{
1 "As quatro estreias de 1969 têm em comum, além das duas personagens e do diálogo não convencional, a meditação sobre um drama crucial do momento. José Vicente, em $O$ Assalto, une revolta existencial contra a injustiça dominante e enfrentamento da temática [da homossexualidade], uma das bandeiras dos direitos das minorias. Fala Baixo Senão Eu Grito, de Leilah Assunção, retrata pela primeira vez a condição da mulher, de uma perspectiva nitidamente feminina. Em À Flor da Pele, Consuelo de Castro confronta a linha comunista ortodoxa e a anarquia, nas implicações no cotidiano de um professor e uma aluna, sua amante. Finalmente Isabel Câmera, em As Moças, dramatiza o relacionamento de duas jovens na luta pela sobrevivência, num grande centro urbano, a que não falta uma delicada sugestão de [lesbianidade]" (MAGALDI, 2006, p. 107).
} 
modo mais sólido, pois se instaurou entre nós, "embora ainda de maneira problemática, uma certa consciência da especificidade da mulher. Começa-se a falar em 'peças escritas por autoras', reconhecendo-se aí uma possível abordagem específica" (ANDRADE, 2006, p. 1). Mais ainda, foi um período em que a mulher passou a alcançar diversos papéis relevantes nos campos da vida cultural e, "com a difusão dos movimentos feministas [...] e a absorção do pensamento das correntes contestatórias dos anos 6o, a presença e continuidade da produção feminina no campo das artes acentuaram-se de forma notável" (ANDRADE, 2006, p. 5).

Mesmo ante os dissabores dos anos 1960, as dramaturgas começaram a ter mais espaço no mercado e na arte teatral. O ponto de partida era a luta pela liberdade e a finalidade de transformação social por meio do teatro. Mas, entre partir e chegar, elas tiveram que enfrentar os percalços da travessia, sobretudo a censura e o silenciamento. Em "Teatro e política no Brasil: os anos 70", Faria (1998) pontua que não é incorreto afirmar que a década de 1960 começou em 1968, quando o regime militar se sentiu ameaçado diante da resistência democrática - representada por diversos setores da sociedade - e promulgou o Ato Institucional no 5 (AI-5). Em

\footnotetext{
Nome de uma suspeita doutrina de segurança nacional, o regime militar arrogava-se o direito de prender trabalhadores, artistas e intelectuais que se opunham à ditadura e de censurar os meios de comunicação e as manifestações artísticas (FARIA, 1998, p. 163).
}

No ensaio "Aspectos do teatro contemporâneo", como um adivinho, Rosenfeld (1993) profetizava que a década de 1960 destacar-se-ia no futuro como uma página notável à história do teatro, graças à explosão de novos talentos, como os já citados Antonio Bivar, José Vicente, Leilah Assunção, Isabel Câmara e Consuelo de Castro.

Pensar o lugar de Consuelo de Castro na dramaturgia contemporânea brasileira, como se observou, evidentemente que não há como desvincular suas peças dos acontecimentos sociopolíticos os quais o Brasil passava em 196o, pois ela vivenciou momentos marcados por duras repressões. A dramaturga é oriunda de uma geração "que despertou para a vida adulta sob o impacto do golpe militar [...], e teve a fase decisiva da 
sua formação intelectual, existencial, cívica e emocional afetada e condicionada pelas consequências desse golpe" (MICHALSKI, 1989, p. 15).

Ao se referir ao ano de 1964, no texto "Cultura: do golpe ao apodrecimento do golpe”, que integra o programa do espetáculo Amor em Campo Minado, de Dias Gomes, Peixoto (1989, p. 57-58) tece os seguintes apontamentos:

Fomos interrompidos por uma força maior: armas metralharam a sede do nosso Centro Popular de Cultura, nosso potencial de expressão e reflexão crítica [...] foi castrado, nossos cantores e músicos foram amordaçados e os militares fardados ou não passaram a vigiar as portas de nossos teatros enquanto seus subalternos mutilavam nossos filmes, logo mais se institucionalizou-se a censura como forma de silenciar nossa imprensa e de proibir a divulgação de nossos poemas e romances.

Pensando na biografia de Consuelo, no dia $1^{\text {o }}$ de abril de 1964, enquanto os militares instalavam-se no poder, ela compareceu ao seu primeiro dia de aula, no curso de Ciências Sociais da Universidade de São Paulo (USP). De 1964 a 1968, Consuelo de Castro esteve "sob a orientação de alguns dos mais admiráveis fazedores de cabeças da época, e tendo como companheiros alguns dos mais carismáticos líderes do movimento estudantil, ela fará um decisivo curso que a deixará para o resto da vida diplomada na ciência de resistir e na arte de indignar-se" (MICHALSKI, 1989, p.15). Como diz Consuelo de Castro (apud MACHADO, 1972, p. 11), sua obra é um "depoimento de uma geração que só herdou violência”.

Nos dias 02 e 03 de outubro de 1968, Consuelo presencia violentos conflitos entre estudantes e policiais, nesse contexto, escreve Prova de Fogo, cuja peça fez com que vivesse na pele as consequências do $\mathrm{AI}-5$, pois foi censurada no mesmo instante. Prova de Fogo foi proibida de ser encenada² por estar em "desacordo" com o Artigo 41 (alíneas “d” e "g”) do Decreto № 20.493, que diz que não será dada autorização para encenação, exibição e transmissão sempre que "d) fôr capaz de provocar incitamento contra o regime vigente, a ordem pública, as autoridades constituídas e sues [sic] agentes" e "g) ferir, por qualquer forma, a dignidade ou o interesse nacionais [sic]" (BRASIL, 1946). Embora silenciada em sua peça de estreia, o talento da jovem autora, como era chamada

\footnotetext{
${ }^{2}$ Na época, Prova de Fogo seria montada pelo Teatro Oficina, sob a direção José Celso Martinez Corrêa

Revista Investigações, Recife, v. 33, n. 1, Dossiê: Literatura Contemporânea de Língua Portuguesa, p. 1 - 27, 2020 ISSN Digital 2175-294x
} 


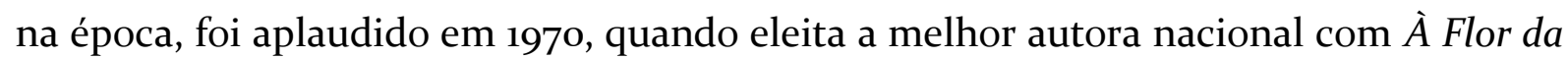
Pele, que na ocasião recebeu o "Prêmio Revelação de Autor" da Associação Paulista de Críticos Teatrais (APCT).

Em termos de linguagem, Consuelo de Castro se desvincula da maioria dos dramaturgos da sua geração, como no caso de Hilda Hilst, que apela à metáfora para driblar a censura. Consuelo, ao contrário, utiliza uma linguagem franca e direta: "Abaixo a ditadura!" (CASTRO, 1989, p. 35). Em Prova de Fogo, para criar uma atmosfera de agitação total - cujo pano de fundo foi a greve estudantil -, a autora sugere, em uma rubrica, que "o teatro todo, inclusive as paredes da própria plateia, poderiam estar repletas de cartazes, desenhos, faixais etc" (CASTRO, 1989, p. 28). Esta rubrica é importante para a construção da peça, pois é um recurso épico, do teatro brechtiano: cartazes e faixas têm a função de "narrar". Em se tratando de um texto que versa sobra a resistência política, Prova de Fogo é um grito contra a repressão. Como bem pontua Magaldi (1989, p. 517), em "Um documento exemplar", quem deseja entender o que ocorreu no Brasil (de 1964 a 1985) "precisará tomar conhecimento da peça. Ela não ilumina apenas um período, mas todo um processo. Deve ser encarada [...] como uma das obras que trouxeram contribuição efetiva à dramaturgia brasileira”.

Após o sucesso da segunda peça, À Flor da Pele, o retorno de Consuelo aos palcos só ocorre em 1974, com Caminho de Volta. Esta peça, escrita quando a autora trabalhava com publicidade, tece um perfil do (sub)mundo das agências publicitárias, uma burguesia em decadência, na qual só há espaço para máquinas desenfreadas lançarem produtos supérfluos e moldarem a consciência humana. Como diz a autora: "só me lembro das máquinas. Gente e máquinas. Trabalhávamos, trabalhávamos e não saíamos do lugar. Então vi uma mosca girando em torno da luz e achei que era eu aquela mosca que não conseguia sair do lugar" (CASTRO apud COURI, 1976, p. 10). Esta experiência, tida pela escritora como um período angustiante, fez com que se desvinculasse dos palcos pois, segundo seu relato, "não conseguia escrever nada que não fosse consumo" (CASTRO apud GRIMALDI, 1976, p. 25) e, por isso o Caminho de Volta "foi exatamente a volta a mim mesma" (CASTRO apud COURI, 1976, p. 10). 
A triste experiência de Consuelo com a censura não para por aí. Benedito da Silva Brasil é uma mulher linda e talentosa, sarcástica e encantadora: este foi o pseudônimo, conforme lembra Couri (1976), assinado pela dramaturga ao escrever O Porco Ensanguentado (1972), revelado apenas na fase do "Concurso Dramático", do Serviço Nacional de Teatro (SNT), em 1974. Neste mesmo ano, embora proibida de ser encenada, a peça recebeu o "Prêmio de Leitura" do SNT. Por conta da censura, este texto de Consuelo ficou mais ensanguentado que o seu Porco, tendo em vista que "ficou um ano para ser liberado pela Censura e veio muito cortado, e tive que abandonar a montagem" (CASTRO apud BEUATTEMMULLER, 1975, p. 5).

A montagem de O Porco Ensanguentado (direção de Carlos Murtinho) só ocorreu em 1976, no Teatro Gláucio Gill, no Rio de Janeiro. Curiosamente, no mesmo ano, Prova de Fogo, premiada em 2o lugar em 1974, foi encenada mesmo sem autorização pelo Grupo de Teatro da Biologia e Ciências Sociais. Em depoimento concedido à revista Aqui, São Paulo, Castro tece os seguintes comentários:

\footnotetext{
Este ano [1976] aconteceu algo que só me motivou para continuar. Um grupo de estudantes resolveu montar a minha peça Invasão dos Bárbaros, a toque de caixa. A peça foi montada na Cidade Universitária, num prédio - o da História - que não estava nem inaugurado. (apud VINCENZO, 1992, p. 109).
}

De acordo com a autora, a "peça ficou quinze dias em cartaz e atraiu mais de 17.0oo pessoas" (CASTRO apud VINCENZO, 1992, p. 109) e, por isso, como pontua Luiz (1989) no texto “Consuelo de Castro desiste dos concursos. A censura não", nenhum aplauso foi mais sonoro.

Como já se observou, por mais que as peças de Consuelo de Castro tenham sido premiadas, elas não escaparam das tesouras afiadas do SNT, mesmo órgão público que, paradoxalmente, concedia prêmios aos dramaturgos. Fato esse que fez com que Castro (apud COURI, 1976, p. 10) se manifestasse indignada: "não entendo como um autor pode ganhar dinheiro do Governo e, ao mesmo tempo, ser acusado de ofender esse mesmo Governo”. Em outra passagem, Consuelo de Castro ressalta:

parece-me absurdo que órgãos de um mesmo Governo distribuam prêmios por um lado e cortes por outro. À Flor da Pele, que recebeu o prêmio da Associação 
Paulista de Críticos, foi censurada tantas vezes que pensei em colocar o diretor do Serviço de Censura, na época Rogério Gomes, como co-autor do texto. Caminho de Volta [...] ficou proibida por 15 dias e sofreu cortes. O Porco sofreu igualmente cortes e ganhou prêmio do SNT. A Invasão dos Bárbaros, também foi premiada no ano em que foi escrita [...] e permaneceu inédita até hoje (CASTRO apud COURI, 1976, p. 10).

Dois meses após o manifesto de Consuelo, o Jornal do Brasil publica uma nota na qual afirma que a classe artística solicita, de imediato, a liberação das peças que foram premiadas pelo SNT: “autores e atores de teatro e televisão pedem ao Ministro que interceda junta à Censura Federal para liberar peças premiadas pelo Serviço Nacional de Teatro" (JORNAL DO BRASIL, 1976, p. 6). O Jornal do Brasil (1976, p. 6) enfatiza que a classe artística sugere “que sejam já liberadas as peças Papa Highirte, 1o lugar em 1968; Rasga Coração, 1o lugar em 1974 - ambas do falecido Oduvaldo Vianna Filho - e $A$ Invasão dos Bárbaros, 2o lugar em 1974, de Consuelo de Castro”.

As atividades do SNT foram suspensas por seis anos, logo após a edição de 1968, na qual Papa Highirte, de Oduvaldo Vianna Filho, foi premiada em º lugar e, em seguida, proibida de ser encenada. As premiações só se reestabeleceram em 1974, cuja edição concedeu o $1^{\text {o }}$ lugar a Rasga Coração, também de Vianinha, e Consuelo recebeu a premiação de 2o lugar com Prova de Fogo. Curiosamente, ambas as peças premiadas foram proibidas de serem levadas à cena. No caso de Vianinha, por conta da censura e de seu falecimento (em 1974), logo após ter sido anunciado o vencedor do SNT, não pode ver encenadas suas peças Papa Highirte e Rasga Coração.

Em 18 de outubro de 1976, o Jornal do Brasil publica uma nota intitulada "O Teatro premiado que não poderá ser visto”, assinada por Maria Lucia Rangel. Neste texto, a autora apresenta mais uma peça de Consuelo que foi proibida pela Censura Federal e não teve liberação para ser encenada: trata-se do drama mítico A Cidade Impossível de Pedro Santana (originalmente Acidente de Trabalho):

Depois de Papa Hihrirte, em 1968, e Rasga Coração, em 1974, mais duas peças premiadas - este ano [1976] - pelo [SNT] não poderão ser vistas pelo público: Acidente de Trabalho, de Consuelo de Castro, e Correntes, de Marcílio Moraes (RANGEL, 1976, p. 5). 
Mesmo recebendo o "Prêmio Leitura Pública" do SNT, A Cidade Impossível de Pedro Santana foi proibida pela censura. Diante de mais esse dissabor, Castro (apud VINCENZO, 1992, p. 110) volta a enfatizar seu manifesto de indignação e, com toda a raiva do mundo, ela faz a seguinte declaração, ao recusar o prêmio concedido pelo SNT: "se alguém quiser me premiar, libere minhas peças. [...] Deixem a gente ir para o palco, que não é de prêmios que precisamos todos, público e escritores: é de liberdade”.

Em entrevista concedida ao Jornal do Brasil, Consuelo de Castro revela que tinha um desejo febril de ver sua peça montada, pois julgava A Cidade Impossível de Pedro Santana - quinta peça escrita - sua obra mais madura. Foram dois anos de pesquisa, inclusive de entrevista com o arquiteto brasileiro Oscar Niemeyer. Na entrevista citada, Consuelo de Castro volta a repudiar o SNT:

\footnotetext{
Desconheço ainda os itens que feri, as leis, os buracos onde me meti sem ser chamada. [...] Diante, então, do sofrimento que tive ao saber da censura de A Cidade Impossível de Pedro Santana, resolvi afirmar meu repúdio a esta contradição (CASTRO apud LUIZ, 1976, p. 10).
}

Em seguida, a dramaturga afirma: "recusarei terminantemente qualquer prêmio que venha do SNT, daqui por diante, ou de qualquer órgão semelhante. Não é hora de solenidades ou prêmios" (CASTRO apud LUIZ, 1976, p. 10).

Liberdade é a chave para que possamos compreender o drama mítico A Cidade Impossível de Pedro Santana, justamente escrita quando Consuelo trabalhava na redação de um fascículo sobre mitologia grega, no qual foi encarregada de estudar o mito de Ícaro e Dédalo, o arquiteto alado. De acordo com a dramaturga, A Cidade Impossível de Pedro Santana "é a transposição do mito para o Brasil de hoje. Esse arquiteto que voa, tenta criar instrumentos (no caso as asas) para atingir a liberdade, é o símbolo da construção, da casa nova" (CASTRO apud LUIZ, 1976, p. 10).

A busca pela liberdade resume, não apenas a produção literária de Consuelo de Castro, mas também de todos os seus companheiros dramaturgos de geração. O lugar que Consuelo de Castro ocupa na dramaturgia brasileira contemporânea foi marcado, 
de fato, pela censura, pela repressão e pelo silenciamento. Em contrapartida, foi marcado também pela luta, pelo combate e pela resistência política. Como diz Vincenzo (1992, p. 110), em Um teatro de mulher: dramaturgia feminina no palco brasileiro contemporâneo, é "a disposição combativa que Consuelo de Castro revela desde sua primeira peça" - o que a torna, de fato, uma das autoras mais importantes da história do drama e do teatro contemporâneo brasileiro.

Consuelo de Castro surge na dramaturgia como uma voz de resistência política. Ela abriu a cortina do último ato, entrou em cena e escreveu o capítulo que faltava na história do teatro brasileiro, um capítulo de consolidação da dramaturgia de autoria feminina. Como diz a autora: "espero apenas assumir meu papel na classe teatral, dedicar-me totalmente a escrever para o teatro brasileiro. Minha luta continuará [...] apesar daqueles que não acreditam” (CASTRO apud BEUTTENMULLER, 1975, p. 5).

\section{Marcha a ré: um drama mítico-expressionista}

A priori, a peça Marcha a Ré, que integra o volume Urgência e Ruptura, apresenta, em sua estrutura dramática, uma ruptura formal. Quando se fala em ruptura formal, estamos nos referindo, sobretudo, às peças teatrais que não apresentam uma sequência linear com começo, meio e fim; tampouco as unidades atribuídas a Aristóteles, de tempo, lugar e ação. O lema de Consuelo de Castro é "romper espaço e tempo" e, como diz a dramaturga, seu intuito é "virar tudo de ponta-cabeça [...], sem o menor temor de me arriscar em terreno desconhecido, me distanciando cada vez mais da fórmula exposição-desenvolvimento-desenlace" (CASTRO, 1989, p. 10).

Esta ruptura formal da estrutura dramática, presente na obra de Consuelo de Castro, aparece pela primeira vez em Script-Tease, peça que apresenta uma quebra na linearidade do enredo ao trazer as personagens Verônica e Verônica 2, sendo que a segunda se trata, apenas, de uma projeção (inconsciente) da primeira no passado. "Em termos da dramaturgia de Consuelo de Castro, a opção formal de Script-Tease é uma experiência inovadora e corajosa” (MICHALSKI, 1989, p. 542-543), a qual também foi utilizada em outras de suas peças, como Aviso Prévio e Marcha a Ré. 
Na unidade de ação, como figura na Poética (1451a 15), de Aristóteles, os acontecimentos devem girar em torno de uma única ação, ou seja, de uma história principal. Nesse sentido, espera-se que o dramaturgo desenvolva um enredo unificado, pois, conforme aponta Aristóteles (Poética,1451a 30), para que o mythos seja uno "é necessário [...] uma ação única e que forma um todo; desse modo, as partes, que constituem os acontecimentos ocorridos, devem ser compostas de tal modo que a reunião ou a exclusão de uma delas diferencie e modifique a ordem do todo”. É justamente essa configuração de unidade de ação que vamos encontrar em peças como Édipo Tirano (427 a. C.), de Sófocles (496-406 a. C.); Hamlet (1601), de William Shakespeare (1564-1616), ou Fedra (1676), de Jean Racine (1639-1699).

Em Marcha a Ré, ao trazer a protagonista Eurídice Alves, que se divide entre Eurídice de Orfeu, Consuelo de Castro recorre à estrutura épica, já que o palco apresenta dois patamares: "o da ação corriqueira - casa de Eurídice Alves - e o da ação mítica [de Eurídice de Orfeu], com texturas rochosas, áridas, num visual que venha sugerir ancestralidade, ruína e bruma" (CASTRO, 1989, p. 474). Esta divisão, por meio de uma forma aberta distingue-se da rigorosa forma cerrada do drama, pois não se restringe a uma ação central, e os patamares fazem com que haja um rompimento da unidade de tempo, lugar e ação, já que esta dispersão suspende "a rigorosa sucessão, continuidade, causalidade e unidade" (ROSENFELD, 2017, p. 33).

De fato, como foi dito na Introdução deste trabalho, Marcha a Ré apresenta um intrínseco diálogo com o mito de Orfeu e Eurídice. Mas não apenas. A referida peça contém cinco atos em diálogos com diversos personagens da mitologia greco-romana, os quais foram punidos eternamente. Assim, o $1^{-}$Ato apresenta uma alusão a Ixião (punido a girar em torno de uma roda em chamas); no $2^{\circ}$ Ato há uma referência a Sísifo (punido a rolar infinitamente uma pedra até o alto da montanha, que cai sempre que chega ao topo); no $3^{\text {o }}$ Ato temos uma menção às Danaides (mulheres punidas, eternamente, a encher um tonel furado); o $4^{\underline{0}}$ Ato traz o mito de Narciso (sinalizado por um espelho que reflete Eurídice solitária e prisioneira de si mesma); e, por fim, o $5^{\circ}$ Ato refere-se a Tântalo (punido eternamente a sentir fome e sede, pois a água e o alimento desaparecem antes que cheguem à boca). 
É importante destacar que os mitos presentes em Marcha a Ré foram escolhidos, pela dramaturga, de modo criterioso. Assim como ocorre com as personagens mitológicas, a protagonista Eurídice Alves também aparece condenada eternamente, mas ao cotidiano e à sua "condição de dona de casa". Por isso que em Marcha a Ré, a pedra de Sísifo aparece sempre que Eurídice sente dores nas costas ao encerar o chão: "cada vez que encero o chão é como se carregasse o mundo nas costas" (CASTRO, 1989, p. 484); a roda de Ixião é sinalizada quando Eurídice está presa ao fogão a picar temperos: "o alho bem miudinho. Três dentões. A cebola bem miudinha. Três grandonas. Cheiroverde ultra, hiper, supermultipicadissimamente" (CASTRO, 1989, p. 479); o tonel das Danaides, simbolicamente, aparece a partir de um armário vazado, do qual a personagem retira diversos produtos: "creme pra ruga, pra flacidez, pra joelho seco, pra pau mole, pra queixo duro, pra bunda grande, pra perna curta, pra pescoço seco, pra pele oleosa, pra... espanador. Outro espanador" (CASTRO, 1989, p. 492); o mito de Narciso, que representa a identidade da personagem "aos pedaços", é evidenciado por meio de espelhos que descem do urdimento e "Eurídice volta-se e se reflete, horrorizada" (CASTRO, 1989, p. 504); por fim, o suplício de Tântalo representa o desejo sexual de Eurídice Alves: "Ela encosta seu corpo no corpo [de Gênio]. Ele se deixa encostar uma vez, mas quando ela vai agudizar sexualmente esta proximidade, ele retira o corpo" (CASTRO, 1989, p. 509).

Consuelo de Castro traz dois universos, aparentemente distintos, que se unem dialogicamente: de um lado, o universo mítico representado pelo mito de Orfeu; do outro, o universo pacato da dona de casa Eurídice Alves. Dentre as versões em que aparece o mito de Orfeu e Eurídice, podemos recorrer à obra Metamorfoses do poeta latino Ovídio - sobretudo aos versos 41-61, do Livro X - que narra a façanha de Orfeu ao adentrar no mundo de Hades no intuito de resgatar sua amada Eurídice, morta após ser picada por uma serpente. Ao tocar sua lira, Orfeu comove o deus infernal que the concede levar Eurídice; mas, com uma condição: não olhar para trás. No entanto, quando faltava pouco para Orfeu sair da região sombria de Hades, 
Esticando os braços, lutando por agarrar-se e ser agarrada, a desgraçada nada apanhou, a não ser o ar fugido. E agora, morrendo por segunda vez, de nada se queixou do marido (de que se queixaria, a não ser de ser amada?). (Metamorfoses, X, vv. 56-61).

Na Antiguidade clássica, hybris é uma palavra utilizada para designar orgulho e arrogância; é a instância que "leva o herói a agir e provocar os deuses, apesar dos seus avisos, o que vai dar na sua vingança ou perda” (PAVIS, 2015, p. 197). A hybris cometida por Orfeu fez com que sua amada ficasse presa eternamente no mundo sombrio de Hades. Semelhantemente, em Marcha a Ré, a protagonista também aparece presa eternamente, mas ao cotidiano e a um passado marcado por profunda repressão política, censura e morte, como foi a ditadura militar no Brasil - um passado, aliás, nem tão longínquo assim. Eurídice Alves também possui uma segunda chance de se libertar de sua prisão eterna. Mas, para isso, é basilar que ela se volte à sua história e à sua consciência no intuito de entender sua condição humana, que não é ser eterna prisioneira. Como diz a protagonista: "devo vagar de corpo em corpo, de solidão em solidão, até encontrar minha origem e meu fim” (CASTRO, 1989, p. 503).

No palco de Marcha a Ré, deparamo-nos com uma situação-limite: é necessário “morrer" para, em seguida, "renascer", pois o "sacrifício" (ou purgação, nos termos aristotélicos) é chave da libertação. No entanto, para que se possa entender o "si mesmo" - o horizonte existencial - o percurso trilhado pela protagonista ocorre a partir do inconsciente, dos desdobramentos do Eu. É necessário regressar, em marcha ré, daí o título da peça. Ao mergulhar no abismo de sua memória, Eurídice Alves deixa transparecer sua "dimensão grotesca - o mergulho abismal, o homem como marionete, o homem cindido (pela impotência e por não saber que é) - atenuada pelo autossacrifício como forma de encontrar-se e, subsidiariamente, construir o Novo Homem” (GARCIA, 1997, p. 28-29). Em suma, trata-se de um drama que versa sobre liberdade; de uma história onde, no último ato, Eurídice Alves se liberta de todas as amarras: do cotidiano, do passado, das repressões familiar e feminina. 
Na medida em que a peça avança, ou regride por meio da memória, entra em cena o "personagem" Gênio, uma espécie de fantasmagoria destinada a levar Eurídice Alves ao mundo oculto e abismal da sua consciência. Aqui, faz-se necessário dizer que o drama mítico Marcha a Ré apresenta uma única personagem, mas que se desdobra e se multiplica em outras, ao longo da peça. No que diz respeito ao Gênio, nas palavras de Vincenzo (1989, p. 553), em "Mito e cotidiano num projeto de puro teatro", trata-se de um daímon "que costuma se apoderar da alma dos heróis para que, à custa de sofrimento, cheguem a conhecer-se a si mesmos como mandam os deuses". Na descrição feita por Consuelo de Castro (1989, p. 473), "Gênio é cruel e terno, abrupto e imprevisível. Apaixonante e apaixonado. Como a consciência”.

Nesse sentido, Gênio representa, na peça, o inconsciente de Eurídice “presentificado” no palco, que insiste em afirmar que ela é Eurídice de Orfeu. Como num sonho delirante, é justamente seu "Eu" que lhe diz para "acordar para tua verdadeira história, tua memória” (CASTRO, 1989, p. 479). Por outro lado, para Eurídice, Gênio é uma "ideia", uma presença absurda e mágica, o que nos leva a pensar, por sua vez, que não passa de uma função abstrata, uma projeção do inconsciente capaz de enviar à mente toda espécie de seres estranhos, fantasmas e imagens grotescas que tendem à ilusão:

EURÍDICE: (Com ódio) Não te vejo! GÊNIO: Não?! Não mesmo?! (Sarcasmo)

EURÍDICE: (Igualmente sarcástica) Não se vê uma ideia! (CASTRO, 1989, p. 492. grifos da autora).

Tudo aquilo que nos é mostrado em cena, nada mais são do que projeções distorcidas do inconsciente de Eurídice, já que ela mesma afirma que sempre esteve sozinha em casa, "como estive toda a minha vida" (CASTRO, 1989, p. 508). Esta assertiva fica mais evidente quando a protagonista nos deixa claro que Gênio não passa de uma "uma voz esquisita”: "picava cebola e alho e veio uma voz esquisita, saída de dentro de mim, da minha língua, dos meus nervos, dos meus instintos, a me dizer que eu não era eu. Que eu era Eurídice, a mulher de um tal Orfeu" (CASTRO, 1989, p. 508). 
Pelo fato de Gênio ser um desdobramento de Eurídice Alves - seu alter ego - temse, em Marcha a Ré, uma projeção através de uma lente subjetiva, isto é, de um Eu central. A protagonista de Marcha a Ré encontra-se sob for pressão emocional e, por conta disso, deixa vazar outros personagens (como é o caso de Gênio) que são, na verdade, mais projeção da consciência de Eurídice Alves. Como se pode depreender a partir do fragmento seguinte, após ouvir a fala de Gênio, Eurídice Alves reage imediatamente à consciência, voltando-se para o corriqueiro do cotidiano:

EURIDICE: (Aturdida. Vagamente ouvindo a fala de Gênio como se ouvisse uma fala interior) Pedra?!... Sísifo! (Reage à consciência: começa a falar corriqueira e naturalmente. Forçando ao máximo uma espontaneidade que já não tem nesse momento) Aqui é minha casa. Rua Lopes Melo, 356. Família Alves. Ao seu dispor. Não seja por isso. O prazer é todo meu. Fique à vontade. Como vão as crianças? Bonito dia hoje, não? Prazer. Muito prazer. Eurídice Alves [...]. (CASTRO, 1989, p. 484. grifos da autora).

Tempo, lugar e ação surgem de modo fragmentado, justamente para retratar a mente conturbada da protagonista: ora estamos no universo coloquial (presente) de Eurídice Alves; ora no universo mítico (passado) de Eurídice de Orfeu; e ora em ambos (presente-passado), simultaneamente. Por isso, em detrimento da ordem cronológica dos fatos, em Marcha a Ré, têm-se saltos temporais, já que se trata de uma sondagem introspectiva. Em Teoria do drama moderno, Szondi (2011, p. 54) afirma que, na "medida em que a trajetória subjetiva toma o lugar da ação objetiva, as unidades de tempo e lugar se tornam [...] caducas. Pois só ganham realidade cênica as curvas singulares desse percurso" (SZONDI, 2011, p. 54).

Neste ponto, é basilar voltar à configuração da forma aberta do drama. O diálogo, base do drama tradicional, não dá mais conta de resolver as forças oriundas do inconsciente, como ocorre em Marcha a Ré e, por isso, torna-se obsoleto. O palco como espaço interno, portanto, "não tende a apresentar o embate de uma personagem [...] vivendo, como na vida real, num tempo sucessivo e irreversível, podendo voltar ao passado apenas através do diálogo que procura articular e exprimir a memória” 
(ROSENFELD, 1993, p.109). Com a crise do diálogo, os dramas, que apresentam o palco como espaço interno (subjetivo), tendem a apresentar

desde logo, visivelmente, cenicamente, a memória ou planos psíquicos mais profundos de uma personagem central. Essa é a única personagem "real", sendo que as outras apenas projeções dessa consciência ou memória centrais. A memória, como o sonho, naturalmente não se atém ao tempo empírico, sucessivo e irreversível. O retrocesso cênico, plástico e visual ao passado - a representação do passado em plena atualidade, em vez de dialogar sobre rompe naturalmente a estrutura tradicional do tempo linear e com isso também o espaço cênico tradicional, já que a variedade dos momentos temporais plenamente atualizados na cena implica a ampliação, variação e superposição espaciais (ROSENFELD, 1993, p. 109-110).

Diante do que veio à baila, podemos depreender que no drama subjetivo ocorre a substituição da unidade de ação pela unidade do Eu. Por conta disso, as cenas não aparecem ligadas de modo "lógico"; pelo contrário, elas "aparecem como contas isoladas, inseridas no fio tecido pelo Eu em seu avanço" (SZONDI, 2011, p. 54). No entanto, no drama subjetivo, aquilo que aparece como alógico, apresenta "a suprema lógica de um ousado salto para o terceiro universo, o do devaneio, do sonho, do pesadelo e da fantasia” (MICHALSKI, 1989, p. 20).

Evidentemente que esta estrutura de drama interior nos conduz a olhar e a analisar a peça de Consuelo a partir de vários ângulos; dentre os quais, podemos destacar a configuração do conflito. No drama naturalista, o indivíduo se vê aprisionado por meio de uma força externa, ou seja, ao ambiente social no qual se insere. De modo oposto, encontramos em Marcha a Ré, pensando tratar-se de um drama interior, um aprisionamento que vem de dentro, isto é, “dos próprios abismos subconscientes que se afiguram anônimos e impessoais" (ROSENFELD, 2017, p. 101).

Por tratar do inconsciente e das projeções psíquicas, podemos dizer, portanto, que Marcha a Ré, em termos de uma filiação estética, apresenta um intrínseco diálogo com o teatro expressionista. No entanto, para que não haja contradição, ou até mesmo anacronismo, tal filiação estética não deve ser vista de modo estanque - trata-se antes de uma aproximação. É justamente tal aproximação que nos leva a identificar na peça Vestido de Noiva (1943), de Nelson Rodrigues (1912-1980), um diálogo com o teatro 
expressionista, pois o dramaturgo brasileiro vale-se dos planos "realidade”, "memória” e “alucinação” para desvendar a mente conturbada da protagonista Alaíde, após sofrer um acidente automobilístico.

Historicamente, o expressionismo foi um movimento artístico que se desenvolveu na Europa, no final do século XIX, caracterizando um dos acontecimentos mais importantes da época, sobretudo por inovar a cena dramática moderna. Dentre suas características, além de partilhar pontos incomuns com o surrealismo, percebe-se uma nítida rejeição ao teatro naturalista. Enquanto este "tentava pintar um quadro realista pelo acúmulo de toda uma riqueza de detalhes reveladores e pequenos, todos eles externos"; o teatro expressionista "descartava-se dos detalhes em favor de um máximo de expressividade" (ESSLIN, 1978, p. 69). Por conta disso, podemos afirmar que o teatro expressionista se volta violentamente contra o passado, combatendo as antigas formas de pensar o drama e, ao mesmo tempo, colocando em primeiro plano a defesa de uma "dramaturgia do eu", ou seja, de uma abordagem extremamente subjetiva.

O teatro expressionista testemunha um período marcado pela crise e pelo embate entre gerações, entre os diferentes modos de ver o mundo: de um lado, "a percepção, a memória e a imaginação"; do outro, "a instância científico empirista do Naturalismo" (GARCIA, 1997, p, 27). Os adeptos da vertente expressionista repudiavam toda e qualquer concepção calcada no materialismo que estava em alta em meados do século XX. A fascinação que se atribuiu à maquinaria do mundo moderno e aos produtos industriais não foi aderida por grande parte dos dramaturgos expressionistas; pelo contrário, eles tendiam a achar que o espírito do indivíduo moderno estava sendo massacrado e esmagado pelo demasiado excesso de desenvolvimento. Diante dessa conjuntura, era esperado que os autores se voltassem para os mistérios que permeiam a vida interior e profunda do Eu; cujo enredo - extremamente fragmentado - surge moldado pelo fluxo de consciência da personagem. No Dicionário de teatro, ao referirse ao espaço interior no drama, Pavis (2015, p. 133) afirma tratar-se de um "espaço enquanto tentativa de representação de uma fantasia, de um sonho, de uma visão do dramaturgo ou de uma personagem”. 
Evidentemente que, na história da dramaturgia moderna, não se pode falar em drama expressionista sem mencionar autores como August Strindberg (1849-1912) e Frank Wedekind (1864-1918). Não se pode negar que nas primeiras peças desses autores há uma tendência ao teatro naturalista. Todavia, como bem pontua Esslin (1978, p. 68) na obra Anatomia do drama, os citados dramaturgos, "fiéis à resolução de representar a experiência exatamente como ela é, em breve descobriram que retratar o mundo externo só conta metade da história”, pois é necessário inserir também o mundo subjetivo que é experenciado pelo indivíduo, o que significa, portanto, falar de seu mundo interior.

Ao se reportar ao dramaturgo Wedekind, autor de O Despertar da Primavera (1891), Patriota (2009, p. 303) afirma que seus temas expressionistas abrigam "uma crítica feroz à sociedade burguesa e à sua moral corrompida. Os seus dramas exigem o abandono desta sociedade e a metamorfose do homem em um 'novo homem". Ainda de acordo com esta autora, Wedekind apresenta em seus dramas uma tendência antinaturalista

na eliminação do sentimentalismo e dos lugares-comuns e leva a condensação da linguagem e a síntese ao estilo telegráfico, incluindo-se na poética expressionista, na medida em que busca a concentração, a abstração e a extrema intensidade de expressão (PATRIOTA, 2009, p. 300).

Já a obra A Caminho de Damasco, de Strindberg, apresenta em sua estrutura uma série de recursos típicos do drama expressionista, sobretudo as personagens tipificadas, geralmente não são nomeadas, apenas identificadas como Velho, Mendigo, Estranho etc. Além disso, em detrimento do desenvolvimento lógico do drama tradicional, esta peça de Strindberg apresenta, como mostra Heliodora (2015, p. 294) em Caminhos do teatro ocidental, uma série de cenas, ou quadros, independentes, os quais "correspondem à progressão do estado de espírito do protagonista”. De acordo com Patriota (2009, p. 304), a fase expressionista de Strindberg "é a forma de expressão pela qual chegou mais perto da nascente de seus sentimentos subterrâneos do eu (medos, fantasias, ambivalências, amor, ódio). É o mergulho no “inconsciente’ ou no 'subconsciente”".

Ainda em relação ao teatro expressionista, leia-se o seguinte fragmento: 
As personagens desdobram-se e multiplicam-se, desvanecem-se e condensam-se, dissolvem-se e reconstituem-se. Mas uma consciência suprema domina a todos: a do sonhador. Para este não existem segredos, inconsequências, escrúpulos, leis. [...] Assim como o sonho é, na maior parte dos casos, mais doloroso do que alegre, a narração, hesitante, é percorrida por uma nota de melancolia e compaixão por tudo o que vive. Embora libertador, o sonho revela-se, penoso, mas, no momento em que é mais intenso o sofrimento, o súbito despertar, que, embora dolorosa, surge agora como uma libertação (STRINDBERG, 1978, p. 1920).

Se este fragmento não fosse do "Prefácio" da peça O Sonho, de Strindberg, dramaturgo expoente do teatro expressionista, sem dúvida, poderia ser atribuído ao drama mítico Marcha a Ré. Isso porque o palco se transforma em um espaço interno; os conflitos são gerados por meio do fluxo de consciência da protagonista: Eurídice Alves desdobra-se em Eurídice de Orfeu; multiplica-se ao representar a Clarisse, amante (imaginária) de seu marido Sebastião; desvanece-se quando o Eu parte em busca do Outro em si mesmo; condensa-se na medida em que o plano "real" e corriqueiro se choca com o universo mítico; e reconstitui-se, no fim da peça, quando a personagem se liberta das amarras repressivas: "aquela roupa molhada na minha pele era tão gostosa, mas tão gostosa, que eu nem liguei pra surra que ia levar. E pra morte que ia morrer" (CASTRO, 1989, p. 511). Liberdade é a tônica de Marcha a Ré. Embora a travessia de Eurídice seja dolorosa, seu súbito despertar é libertador.

$\mathrm{Na}$ desenfreada procura pela liberdade, em tempos e lugares distintos, Eurídice Alves está cercada, como já mencionado, de outras personagens (Gênio, Sebastião, Clarisse), frutos apenas de sua consciência. "Se a personagem se fragmenta [é] porque o autor quer mostrar que ela é uma soma de máscaras, tem vários eus" (CANDEIAS, 2012, p. 19). Por este motivo, conforme pontua Sarrazac (2017, p. 136), em Poéticas do drama moderno: de Ibsen a Koltè, o drama expressionista "emprestou de Strindberg sua tendência a uma dramaturgia na primeira pessoa em que tanto o mundo material como as demais personagens gravitam em torno do protagonista, que segue adiante, perseguindo seu sonho, sua errância".

Além do que já foi exposto, é importante destacar, ainda, outros aspectos cênicodramáticos presentes em Marcha a Ré que se aproximam do teatro expressionista. Assim 
como a estrutura geral da peça (divisão por meio de atos/quadros, tempo, lugar e ação), que tende à fragmentação; a linguagem utilizada por Consuelo de Castro também surge de modo fragmentada e, em muitas das vezes, até mesmo "violando a palavra através de sua substituição por ruídos, sons, gritos etc" (BORNHEIM, 2007, p. 67), como se pode averiguar na abertura no $4^{\mathrm{o}}$ Ato:

(Acende luz estroboscópica. Objetos caem por trás do telão: cadeiras, eletrodomésticos, colchão, etc.[...] Ruídos estrondosos de armário sendo quebrado à marreta. Luz para e volta [...]. Vozes femininas rudes comentários de rua. Pânico, curiosidade. Trilha mistura estes barulhos aos de sirene. Choro de criança pequena. Murmúrios noturnos, ronco de homem velho. Risadas de mulher enlouquecida. Eurídice sai totalmente desgrenhada da coxia direita, correndo para a coxia esquerda, como se procurasse alguém [...], totalmente desorientada e furiosa, corre de um lado para o outro) (CASTRO, 1989, p. 497. grifos da autora).

Do mesmo modo, podemos identificar que as regras sintáticas de Marcha a Ré aparecem, em diversas passagens, submetidas a um desordenamento delirante, resultado da subjetividade emocional de Eurídice Alves. No fragmento seguinte, para "ilustrar" a mente conturbada da protagonista, Consuelo sugere que as frases corriqueiras e desconexas se misturem aos ruídos insuportáveis de um liquidificador. Mais ainda, como se a cabeça da personagem, em agitação total, fosse o próprio liquidificador.

(Trilha sobe no ruído de migração de pássaros e silencia de vez. Abrupto blackout. Gênio desaparece no black-out. Foco mínimo acende fulminantemente em Eurídice após black-out. [...]. Ela caminha para a plateia, e na boca de cena, para e meneia a cabeça; barulho seco de latas. [...] A cabeça gira mais e mais veloz. Ruído de liquidificador entra e sobe insuportavelmente. A atriz agora é um liquidificador perfeito. Frases corriqueiras mixam-se a ruídos de liquidificador).

FRASES EM OFF: Mão/ Pé/ Três pagamentos sem acréscimo/ Dona Dicinha, empresta o balde?/ três de coxão mole/ Cebola/ Esmola pelo amor de Deus? Aquela cor ali/ A mendiga do farol/ Clarisse, cê viu?/ Pega a bola Tião/ O fiscal voltou, meu bem/ Quem não deve/ O sono é o prelúdio da morte/ Sócio da light/ Uma dor nas costas/ Depois que casar passa (CASTRO, 1989, p. 49o. grifos da autora).

Tendo ainda como ponto de partida os fragmentos anteriores, podemos tecer, por fim, um breve comentário sobre a iluminação da peça, que também é dotada de 
expressividade. "Com a chegada do expressionismo, a luz retoma e amplia características herdadas da pintura barroca (contrastes e transições entre claro e escuro), acrescentando dramaticidade e subjetivismo" (CAMARGO, 2012, p. 48). No palco expressionista predominam as deformações, as manchas, as sombras, os focos, as projeções e flashes, tendendo à uma atmosfera sombria, e que "possibilite a desnaturalização e a expressão do objeto, do sujeito ou da forma em si mesma" (CAMARGO, 2012, p. 48). Em Função estética da luz, segundo aponta Camargo,

\footnotetext{
os projetores dividiam a cena, tirando da escuridão cones de realidade mágica, como projeções subjetivas do protagonista. Em palcos quase vazios, a iluminação estabelecia contrastes violentos do claro-escuro, reforçando a expressividade (CAMARGO, 2012, p. 48-49).
}

Na construção dramática de Marcha a Ré, em detrimento da iluminação geral comumente presente no drama tradicional - encontram-se diversas indicações de iluminações, tais como: "escuro total", "black-out", "foco flamejante e mínimo", "luz silhueta", "luz intensamente verde, misteriosa, instigante e perigosa”, “o telão se apaga”, “abrupto black-out”, "black-out fulminante”, "penumbra”, "foco mínimo acende fulminantemente após black-out" etc. Todas essas expressões, exploradas por Consuelo de Castro, ao máximo, durante a peça, "são capazes de estabelecer um isolamento do ator, separando-o do restante, suprimindo-lhe a relação com o mundo exterior" (CAMARGO, 2012, p. 48), o que apenas evidencia a angústia interior da personagem Eurídice Alves, na sua desenfreada busca pela libertação.

\section{Considerações finais}

O drama mítico-expressionista Marcha a Ré, de Consuelo de Castro, assim como muitas obras do teatro expressionista, volta-se contra o passado. No caso da dramaturga brasileira, o voltar-se ao passado, refere-se às amarras repressivas oriundas da Ditadura Militar no Brasil. Reportando-se às peças escritas na década de 1980, Vincenzo (1992) identifica que em meados dos anos 8o, houve uma tendência, por parte dos 
dramaturgos, de inserir certos elementos que se reportavam ao passado recente do país. Mais adiante, Vincenzo (1992, p. 176) ressalta: “o que permite ver no conjunto a linha de uma tendência comum [...] é o fato de essas peças mostrarem ou referirem o passado recente através da lembrança ou das consequências de acontecimentos vividos na vida presente das personagens".

Então, podemos pensar que Marcha a Ré também se insere nessa nova tendência, mas com uma particularidade: não temos um diálogo direto com o passado recente do Brasil. Por tratar-se de uma peça de traços expressionistas, em Marcha a Ré, o elemento político transforma-se em um discurso indireto, o que desemboca numa linguagem permeada pelo simbolismo. No teatro expressionista, portanto, "são evidentes as preocupações sociais, nem sempre claras, visando à criação de um "novo homem"' (GUINSBURG; FARIA; LIMA, 2009, p. 151). Se nas primeiras peças de Consuelo de Castro o "grito" político é externo, como ocorre em Prova de Fogo; nas peças escritas a partir de 1980, que inclui Marcha a Ré, o "grito" político contra aquilo que nos prende é interno, pois se trata de um drama interior, ou seja, de traço expressionista.

Consuelo de Castro traz à baila uma personagem feminina, a fim de descortinar toda espécie de repressão e de silenciamento. Assim, é esperado que a personagem "renasça”, distante de todas as amarras que a mantém presa. Nesse ponto, a negação de Eurídice Alves de se reconhecer como Eurídice Mítica torna-se justificável. O fato de a protagonista aparecer desprovida de identidade (ou uma identidade fragmentada) nada mais é do que o reflexo de um período histórico pós-ditatorial, no qual o ser humano “perdeu sua identidade”, já que sua liberdade de expressão fora negada.

Como pontua Magaldi (1997), em Panorama do teatro brasileiro, com o fim da Ditadura Militar no Brasil, criou-se um inevitável vazio. É justamente esse vazio que está refletido em Marcha a Ré, e que faz a personagem seguir, em marcha a ré, a procura de uma nova identidade. De modo semelhante ocorreu no contexto do surgimento do teatro expressionista, pois conforme aponta Bornheim (2007, p. 67), no ensaio "Duas características do expressionismo”, a conservação “da identidade da personagem supõe que a História seja datada de sentido; mas estamos, apocalipticamente, no fim da 
História, na 'decadência do Ocidente'. E se a História perde sua consistência segue-se fatalmente a dissolução da personagem”.

Nesse sentido, Marcha a Ré representa este vazio que nos obriga a buscar a liberdade e a identidade após um período marcado por silenciamento, tortura, perseguições políticas e mortes. Se entre 1968 e 1978 Consuelo escreveu peças sob a pressa rangente dos fatos, nas quais traça um exame da condição existencial do ser humano, nas produções que se seguiram, isto é, a partir da década de 1980, ela procurou evidenciar a autoafirmação feminina no contexto pós-ditadura.

Resta-nos, portanto, nos reconstituirmos, assim como Eurídice Alves, no último ato; despedaçada, ela começa a reconstituir sua identidade, colocando os membros que lhe foram retirados: "começa um ritual perplexo de recompor a boneca: sua identidade nesse instante" (CASTRO, 1989, p. 507. grifos da autora). Se a chave do expressionismo - ao menos a partir de um quadro geral - é a busca pela libertação a fim de construir um “novo homem", uma nova sociedade; Marcha a Ré é a chave para pensar a liberdade feminina no período pós-ditadura; assim como foi, no seu modo e contexto, para os “heróis” expressionistas no período da Primeira Guerra Mundial.

\section{Referências}

ANDRADE, A. L. V. de. Margem e centro: a dramaturgia de Leilah Assunção, Maria Adelaide Amaral e Ísis Baião. São Paulo: Perspectiva, 2006.

ARISTÓTELES. Poética. Trad. de Paulo Pinheiro. São Paulo: Editora 34, 2015.

BORNHEIM, G. “Duas características do expressionismo”. In: O sentido e a máscara. 3. ed. São Paulo: Perspectiva. p. 64-68, 2007.

BEUTTENMULLER, A. “A má fase do teatro no mundo da publicidade”. Jornal do Brasil. p. 5, 2 abr. 1975 .

BRASIL. DECRETO № 20.493, DE 24 DE JANEIRO DE 1946. Regulamento do Serviço de Censura de Diversões Públicas do Departamento Federal de Segurança, Brasília, jan. 1946. CAMARGO, R. G. Função estética da luz. 2. ed. São Paulo: Perspectiva, 2012. 
CANDEIAS, M. L. L. A fragmentação da personagem: no texto teatral. São Paulo: Perspectiva, 2012.

CASTRO, C. de. "Marcha a Ré”. In: Urgência e Ruptura. São Paulo: Perspectiva, p. 572511, 1989 .

. “Prova de Fogo”. In: Urgência e Ruptura. São Paulo: Perspectiva, p. 26-117, 1989 .

“Um bloco de sulfite”. In: Urgência e Ruptura. São Paulo: Perspectiva, p. 9-11, 1989.

“CONSUELO DIZ COMO FEZ ‘A FLOR DA PELE”. Tribuna da Imprensa. p. 5, 18 mai. 1972.

COURI, N. “Consuelo de Castro: o sangue, a censura e o porco". Jornal do Brasil. p. 10, 29 abr. 1976.

ESSLIN, M. Anatomia do drama. Trad. de Barbara Heliodora. Rio de Janeiro: Editora Zahar, 1978.

FARIA, J. R. “Teatro e política no Brasil: os anos 70”. In: O teatro na estante. São Paulo: Ateliê Editorial, p. 163-174, 1998.

GARCIA, S. As trombetas de Jericó: teatro das vanguardas históricas. São Paulo: Hucitec, 1997.

GRIMALDI, E. “Consuelo leva ao teatro a violência da sociedade”. O Fluminense. p. 5, 23 fev. 1976.

GUARNIERI, G. "A respeito de Consuelo de Castro”. In: CASTRO, C. de. A cidade impossível de Pedro Santana. São Paulo: Vanguarda, p. 5-7, 1978.

GUINSBURG, L; FARIA, J. R.; LIMA, M. A. de. Dicionário do teatro brasileiro: temas, formas e conceitos. 2. ed. São Paulo: Perspectiva: Edições SESC SP, 2009.

HELIODORA, B. Caminhos do teatro ocidental. São Paulo: Perspectiva, 2015.

LUIZ, M. “Consuelo de Castro desiste dos concursos. A censura não”. Jornal do Brasil. p. 10, 3 nov. 1976.

MACHADO, G. S. “Colunão”. Tribuna da Imprensa. p. 11, 18 jan. 1972.

MAGALDI, S. “Um documento exemplar”. In: CASTRO, C. de. Urgência e Ruptura. São Paulo: Perspectiva, p. 515-517, 1989. 
Panorama do teatro brasileiro. 3. ed. São Paulo: Global Editora, 1997.

. “O teatro social no Brasil contemporâneo”. In: Teatro sempre. São Paulo:

Perspectiva, 97-116, 2006.

MICHALSKI, Y. "Consuelo de Castro: Sempre urgente. Sem rupturas”. In: CASTRO, C. de. Urgência e Ruptura. São Paulo: Perspectiva, p. 13-24, 1989.

. "Desnudamento ético". In: CASTRO, C. de. Urgência e Ruptura. São Paulo: Perspectiva, p. 539-543, 1989.

OVÍDIO. Metamorfoses. Trad. de Paulo F. Alberto. Lisboa: Livros Cotovia, 2007. PATRIOTA, R. "Uma breve nota acerca de inúmeras anotações”. In: GUINSBURG, J, 2009. . J. Guinsburg, a cena em aula: itinerário de um professor em devir. São Paulo: Editora da Universidade de São Paulo, 2009.

PAVIS, P. Dicionário de teatro. Trad. de J. Guinsburg e Maria Lúcia Pereira. 3. ed. São Paulo: Perspectiva, 2015.

PEIXOTO, F. “Cultura: do golpe ao apodrecimento do golpe”. In: Teatro em questão. São Paulo: Editora Hucitec, p. 57-6o, 1989.

RANGEL, M. L. “O Teatro premiado que não poderá ser visto”. Jornal do Brasil. p. 5, 18 out. 1976 .

ROSENFELD, A. "Aspectos do teatro moderno". In: Primas do teatro. São Paulo: Perspectiva, p. 107-112, 1993.

. “Aspectos do teatro contemporâneo". In: Primas do teatro. São Paulo: Perspectiva, pp. 199-206, 1993.

. O teatro épico. 6. ed. São Paulo: Perspectiva, 2017.

RIANI, M. "Encontro dos tempos de chumbo com os anos 9o". Jornal do Brasil. p. 2, 10 mar. 2001.

STRINDBERG, A. "Prefácio". In: O Sonho. Trad. de João da Fonseca Amaral. Lisboa: Estampa, p. 9-20, 1978.

SARRAZAC, J-P. Poética do drama moderno: de Ibsen a Koltè. Vários tradutores. São Paulo: Perspectiva, 2017.

SZONDI, P. Teoria do drama moderno. 2. ed. Trad. de Raquel Imanishi Rodrigues. 2. ed. São Paulo: Cosac \& Naify, 2011. 
“TEATRO PEDE A NEI QUE LIBERE PEÇAS PREMIADAS”. Jornal do Brasil. p. 6, 26 jun. 1976.

VINCENZO, E. C. de. Um teatro de mulher: dramaturgia feminina no palco brasileiro contemporâneo. São Paulo: Perspectiva; Edusp, 1992.

. "Mito e cotidiano num projeto de puro teatro". In: CASTRO, C. de. Urgência e Ruptura. São Paulo: Perspectiva, p. 551-554, 1989.

WAJNBERG, D. S. "Consuelo de Castro, autora de 'Only You', faz balanço de sua trajetória”. Tribuna da Imprensa, p. 1, 21 mar. 2003.

Recebido em 06/03/2020.

Aprovado em 17/05/2020. 